\title{
Streaming Potential and Zeta Potential Measurements in Porous Rocks
}

\author{
Luong Duy Thanh \\ Thuyloi University, Hanoi, Vietnam \\ Email: luongduythanh2003@yahoo.com
}

How to cite this paper: Thanh, L. D. (2018). Streaming Potential and Zeta Potential Measurements in Porous Rocks. Journal of Geoscience and Environment Protection, 6, 89-100. https://doi.org/10.4236/gep.2018.611007

Received: June 19, 2018

Accepted: November 18, 2018

Published: November 21, 2018

Copyright $\odot 2018$ by author and Scientific Research Publishing Inc. This work is licensed under the Creative Commons Attribution International License (CC BY 4.0).

http://creativecommons.org/licenses/by/4.0/

(c) (i) Open Access

\begin{abstract}
The measurements of the streaming potential coefficient and the zeta potential of two consolidated samples saturated with four monovalent electrolytes at different electrolyte concentrations have been performed. The experimental results show that the streaming potential coefficient and the zeta potential in magnitude both decrease with increasing electrolyte concentration for all electrolytes. It is also shown that there is a dependence of the streaming potential coefficient on types of electrolyte for a given sample. This is explained by the dependence of the zeta potential and the electrical conductivity on types of electrolyte. Additionally, the variation of the zeta potential with types of electrolyte is also reported and qualitatively explained. From experimental data on the streaming potential coefficient and the zeta potential, the empirical expressions between the streaming potential coefficients, the zeta potential and electrolyte concentration are also obtained. The obtained expressions have the similar forms to those available in literature. However, there is a deviation between them due to dissimilarities of fluid conductivity, fluid $\mathrm{pH}$, mineral composition of porous materials and temperature.
\end{abstract}

\section{Keywords}

Streaming Potential Coefficient, Zeta Potential, Porous Media, Rocks, Electrolytes

\section{Introduction}

The streaming potential is induced by the relative motion between the fluid and the solid surface. In porous media such as rocks, sands or soils, the electric current density, linked to the ions within the fluid, is coupled to the fluid flow. Streaming potential plays an important role in geophysical applications. For example, the streaming potential is used to map subsurface flow and detect sub- 
surface flow patterns in oil reservoirs (e.g., Wurmstich \& Morgan, 1994). Streaming potential is also used to monitor subsurface flow in geothermal areas and volcanoes (e.g., Corwin \& Hoover, 1979; Morgan, Williams, \& Madden, 1989). Monitoring of streaming potential anomalies has been proposed as a means of predicting earthquakes (e.g., Mizutani, Ishido, Yokokura, \& Ohnishi, 1976; Trique, Richon, Perrier, Avouac, \& Sabroux, 1999) and detecting of seepage through water retention structures such as dams, dikes, reservoir floors, and canals (e.g., Ogilvy, Ayed, \& Bogoslovsky, 1969).

The streaming potential coefficient (SPC) is a very important parameter in geophysical applications, since this parameter controls the amount of coupling between the fluid flow and the electric current in porous media. The SPC of liquid-rock systems is theoretically a very complicated function depending on many parameters (e.g., Glover, Walker, \& Jackson, 2012). At a given porous rock, the most influencing parameter is the fluid conductivity. Therefore, it is useful to have an empirical relation between the SPC and fluid conductivity or electrolyte concentration that has been obtained by Jouniaux \& Ishido (2012) and Vinogradov, Jaafar, \& Jackson (2010) by fitting experimental data available in literature for consolidated rocks. However, experimental data sets used for fitting are from different sources with dissimilar fluid conductivity, fluid $\mathrm{pH}$, temperature, mineral composition of porous media. All those dissimilarities may cause the empirical expressions less accurate. Additionally, empirical expressions are different for different types of porous media and types of electrolytes. Recently, Thanh \& Rudolf (2018) have obtained the empirical relation between the SPC and electrolyte concentration by fitting their own experimental data but for unconsolidated sand packs. In this work, the streaming potential measurement has been performed for two consolidated rocks saturated by four monovalent electrolytes $(\mathrm{NaCl}, \mathrm{NaI}, \mathrm{KCl}$ and $\mathrm{KI})$ at six different electrolyte concentrations $\left(10^{-4} \mathrm{M}, 5.0 \times 10^{-4} \mathrm{M}, 10^{-3} \mathrm{M}, 2.5 \times 10^{-3} \mathrm{M}, 5.0 \times 10^{-3} \mathrm{M}\right.$, and $\left.10^{-2} \mathrm{M}\right)$.

The experimental data on the SPC show that there is a dependence of the SPC on types of electrolyte for a given sample. This is explained by the dependence of the zeta potential and the electrical conductivity on types of electrolyte. The empirical expression between the SPC and electrolyte concentration is obtained. The obtained expression has similar form to those obtained by Jouniaux \& Ishido (2012); Vinogradov, Jaafar, \& Jackson (2010) and Thanh \& Rudolf (2018) in which the SPC in magnitude is inversely proportional to electrolyte concentration. Additionally, the zeta potential of the liquid-rock systems is also determined from the measured SPC. An empirical relation between the zeta potential and electrolyte concentration is also obtained and it has the same behavior as those reported in literature (e.g., Vinogradov, Jaafar, \& Jackson, 2010; Pride \& Morgan, 1991). However, the prediction from available empirical expression overestimate the zeta potential measured in this work. The reason for the overestimation may be due to dissimilarities of fluid conductivity, fluid $\mathrm{pH}$, mineral composition of porous material and temperature etc. at which the experiments are carried out. 


\section{Theoretical Background of Streaming Potential}

When a porous medium is saturated with an electrolyte, an electric double layer (EDL) is formed on the interface between the solid and the fluid (e.g., Jacob \& Subirm, 2006). The EDL is made up of the Stern layer, where ions are adsorbed on the solid surface and are immobile and the diffuse layer, where the ions remain movable in the fluid. In the bulk liquid, the number of positive ions and negative ions is equal so that it is electrically neutral. The closest plane to the solid surface in the diffuse layer at which flow occurs is termed the shear plane or the slipping plane, and the electrical potential at this plane is called the zeta potential $(\zeta)$.

If the fluid is induced to flow tangentially to the interface of the capillary by a fluid pressure drop (a porous medium can be approximated as an array of parallel capillaries), and then some excess ions within the diffuse layer are transported with the flow, giving rise to a streaming current. This streaming current is balanced by a conduction current, leading to the streaming potential (see Figure 1). In a fluid saturated porous medium, the electric current and the fluid flux are coupled, so fluids moving through porous media generate a streaming potential (Nourbehecht, 1963). The streaming potential increases linearly with the fluid pressure difference that drives the fluid flow, provided that the flow remains laminar. The steady state SPC is defined when the total current density is zero as (e.g., Jouniaux \& Ishido, 2012)

$$
C_{S}=\frac{\Delta V}{\Delta P}=\frac{\varepsilon_{r} \varepsilon_{o} \zeta}{\eta \sigma_{e f f}},
$$

where $\Delta V$ is the streaming potential, $\Delta P$ is the fluid pressure difference, $\varepsilon_{r}$ is the relative permittivity of the fluid, $\varepsilon_{o}$ is the dielectric permittivity in vacuum, $\eta$ is the dynamic viscosity of the fluid, $\sigma_{\text {eff }}$ is the effective conductivity, and $\zeta$ is the zeta potential. The effective conductivity includes the fluid conductivity and the surface conductivity. The SPC can also be written as (Jouniaux \& Ishido, 2012)

$$
C_{S}=\frac{\varepsilon_{r} \varepsilon_{o} \zeta}{\eta F \sigma_{r}}
$$

where $\sigma_{r}$ is the electrical conductivity of the sample saturated by a fluid with a conductivity of $\sigma_{f}$ and $F$ is the formation factor. The electrical conductivity of the

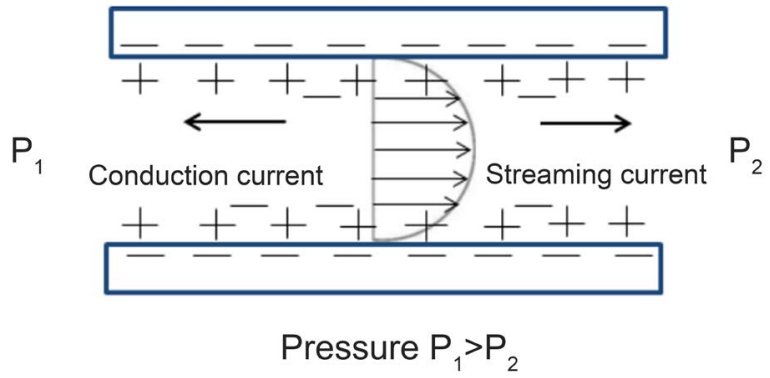

Figure 1. Development of streaming potential when an electrolyte is pumped through a capillary. 
sample can possibly include surface conductivity. If the fluid conductivity is much higher than the surface conductivity, the effective conductivity is approximately equal to the fluid conductivity $\sigma_{e f f}=F \sigma_{r}=\sigma_{f}$ and the SPC is reduced to:

$$
C_{S}=\frac{\varepsilon_{r} \varepsilon_{o} \zeta}{\eta \sigma_{f}}
$$

\section{Experiment}

\subsection{Materials}

Streaming potential measurements have been performed on cylindrical rock samples of $55 \mathrm{~mm}$ in length and $25 \mathrm{~mm}$ in diameter. Two rock samples are selected for this work (see Figure 1): one sample (sample 1) is Berea sandstone; the other one (sample 2) is an artificial ceramic. The micro structure properties and sources of the samples have been reported in Thanh \& Sprik (2016); Luong (2014) and re-shown in Table 1.

Four monovalent electrolytes $(\mathrm{NaCl}, \mathrm{NaI}, \mathrm{KCl}$ and $\mathrm{KI})$ are used with 6 different electrolyte concentrations $\left(10^{-4} \mathrm{M}, 5.0 \times 10^{-4} \mathrm{M}, 10^{-3} \mathrm{M}, 2.5 \times 10^{-3} \mathrm{M}, 5.0 \times\right.$ $10^{-3} \mathrm{M}$, and $\left.10^{-2} \mathrm{M}\right)$. All measurements are performed at room temperature $\left(22^{\circ} \mathrm{C} \pm 1^{\circ} \mathrm{C}\right)$.

\subsection{Experimental Setup}

The experimental setup for the streaming potential measurement is shown in Figure 2. The solution is circulated through the samples until the electrical conductivity and $\mathrm{pH}$ of the solution reach a stable value measured by a multimeter (Consort C861). The average value of $\mathrm{pH}$ is around 6.8. Electrical potential differences across the samples are measured by a high input impedance multimeter (Keithley Model 2700). A high-precision differential pressure transducer (Endress and Hauser Deltabar S PMD75) is used to measure pressure differences across the samples.

The way used to collect the SPC is similar to that described in Thanh \& Sprik (2016); Luong (2014). Figure 3 shows an example of the streaming potential as a function of pressure difference at electrolyte concentration of $5 \times 10^{-3} \mathrm{M}$ for sample 2 and NaI electrolyte. The SPC is then obtained as the slope of the straight line (see the fitting line in Figure 3). Three measurements are performed to find the average value of the SPC.

Table 1. Sample ID, mineral compositions and microstructure parameters of the samples. Symbols $k_{o}$ (in $\mathrm{mD}$ ), $\phi$ (in \%), $F$ (no units), $\alpha_{\infty}$ (no units) stand for permeability, porosity, formation factor and tortuosity of porous samples, respectively.

\begin{tabular}{ccccccc}
\hline \multicolumn{2}{c}{ Sample ID } & Mineral compositions & $k_{o}$ & $\Phi$ & $F$ & $\alpha_{\infty}$ \\
\hline 1 & Sample 1 & $\begin{array}{c}\text { Silica, Alumina, Ferric Oxide, Ferrous Oxide } \\
(\underline{\text { https://www.bereasandstonecores.com/) }}\end{array}$ & 310 & 20.1 & 14.5 & 2.9 \\
2 & Sample 2 & $\begin{array}{c}\text { Alumina and fused silica } \\
(\text { see: } \underline{\text { http://www.tech-ceramics.co.uk/) }}\end{array}$ & 430 & 44.1 & 5.0 & 2.0 \\
\hline
\end{tabular}



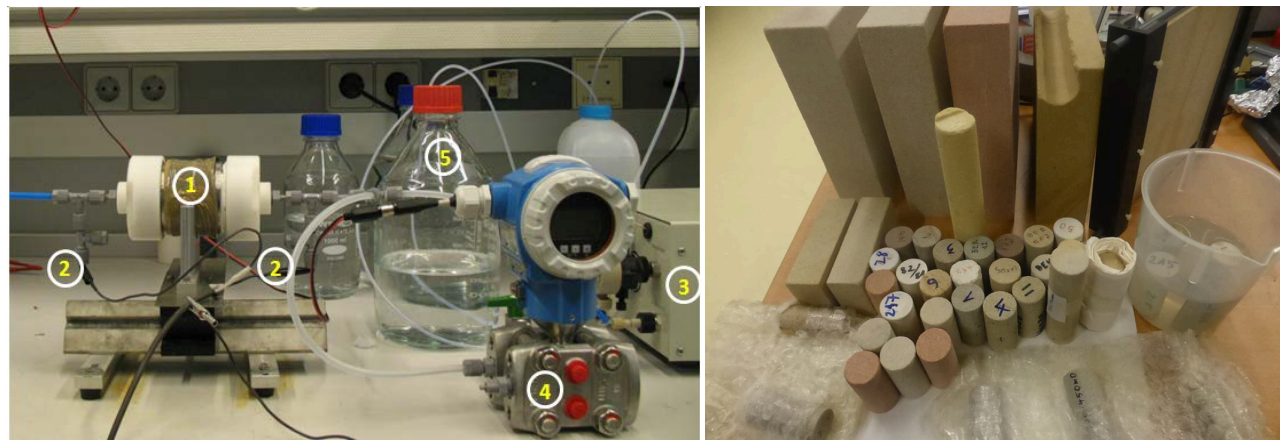

Figure 2. Experimental setup for streaming potential measurements. 1, Core holder; 2, Ag/AgCl electrodes; 3, Pump; 4, Pressure transducer; 5, Solution container and the rock samples used in this work.

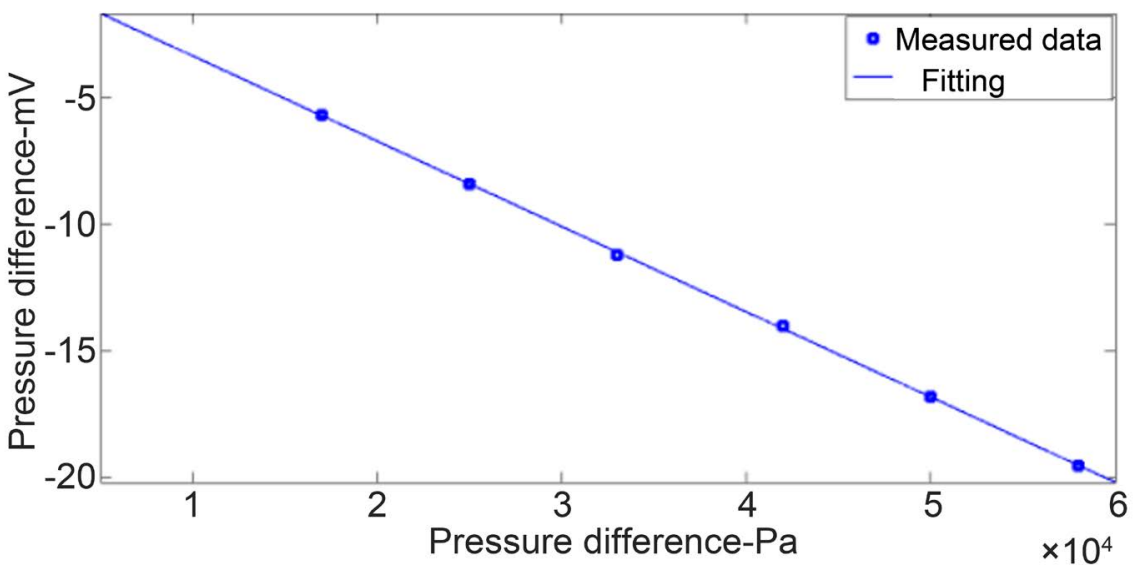

Figure 3. Streaming potential versus pressure difference at a concentration of $5.0 \times 10^{-3} \mathrm{M}$ for sample 2 and $\mathrm{NaI}$.

\section{Results and Discussion}

\subsection{Streaming Potential Coefficient}

The measured SPC at different electrolyte concentrations is shown in Table 2. The maximum error of the SPC is 10\%. It is found that the SPC is negative for all electrolytes and the SPC magnitude decreases with increasing electrolyte concentration as expected in literature (e.g., Glover, Walker, \& Jackson, 2012). From Table 2, the variation of the SPC with types of electrolyte for both samples is shown in Figure 4. The experimental results also show that the SPC is different for different types of electrolyte at the same concentration for a given sample. Namely, the magnitude of the SPC increases in the order from $\mathrm{KCl}, \mathrm{KI}, \mathrm{NaCl}$ and $\mathrm{NaI}$, respectively. This can be explained by the variation of the fluid conductivity and the zeta potential with types of electrolyte. For the electrolytes used in this work, the variation of the electrical conductivity with electrolyte concentration is described by the Debye-Hückel-Onsager equation (Lide, 2009)

$$
\Lambda=\Lambda^{o}-\left(A+B \Lambda^{o}\right) c^{1 / 2},
$$

where $\Lambda$ is the molar conductivity (in $10^{-4} \mathrm{~m}^{2} \mathrm{~S} \mathrm{~mol}{ }^{-1}$ ), $\Lambda^{o}$ is limiting molar 
Table 2. The streaming potential coefficient (mV/bar) for different electrolyte concentrations.

\begin{tabular}{cccccccc}
\hline Sample ID & Electrolyte & $10^{-4} \mathrm{M}$ & $5 \times 10^{-4} \mathrm{M}$ & $10^{-3} \mathrm{M}$ & $2.5 \times 10^{-3} \mathrm{M}$ & $5 \times 10^{-3} \mathrm{M}$ & $10^{-2} \mathrm{M}$ \\
\hline \multirow{5}{*}{ Sample 1 } & $\mathrm{NaCl}$ & -160 & -122 & -90 & -45 & -26 & -15 \\
& $\mathrm{NaI}$ & -169 & -128 & -93 & -46 & -28 & -16 \\
& $\mathrm{KCl}$ & -110 & -74 & -58 & -32 & -20 & -12 \\
& $\mathrm{KI}$ & -139 & -97 & -78 & -38 & -25 & -13 \\
& $\mathrm{NaCl}$ & -407 & -220 & -130 & -77 & -32 & -17 \\
\multirow{5}{*}{ Sample 2 } & $\mathrm{NaI}$ & -426 & -235 & -132 & -79 & -34 & -18 \\
& $\mathrm{KCl}$ & -385 & -165 & -84 & -46 & -28 & -14 \\
& $\mathrm{KI}$ & -396 & -187 & -98 & -47 & -29 & -16 \\
\hline
\end{tabular}

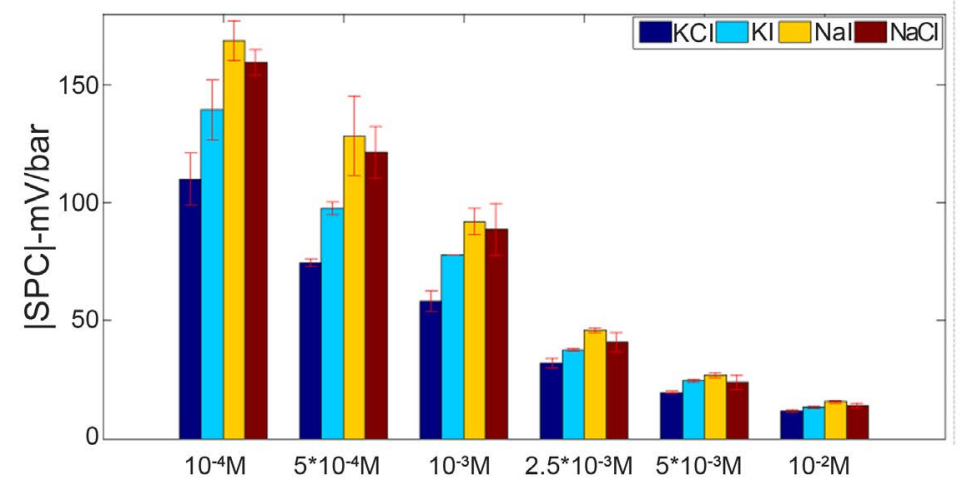

(a)

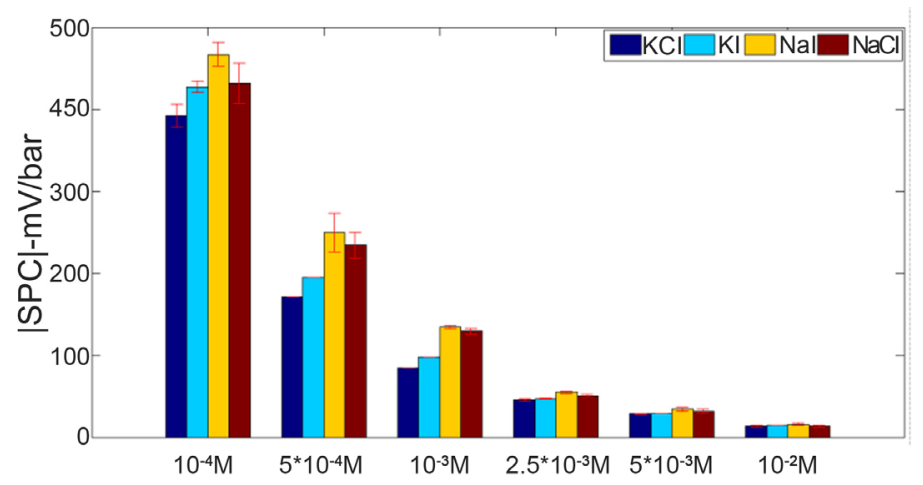

(b)

Figure 4. The Variation of the SPC magnitude with types of electrolyte for sample 1 (a) and sample 2 (b).

conductivity, $A$ and $B$ are constants ( $A=60.20, B=0.229$ ), $c$ is electrolyte concentration. For dilute solutions, the values of $\Lambda^{\circ}$ for is $\mathrm{KCl}, \mathrm{KI}, \mathrm{NaCl}$ and $\mathrm{NaI}$ are $149.79,150.31,126.39,126.88\left(10^{-4} \mathrm{~m}^{2} \cdot \mathrm{S} \cdot \mathrm{mol}^{-1}\right)$, respectively. From Equation (4), the variation of the molar conductivity with electrolyte concentration for different electrolytes is shown in Figure 5. It is deduced that at the same electrolyte concentration, the electrical conductivities of $\mathrm{KCl}$ and $\mathrm{KI}$ that are almost 


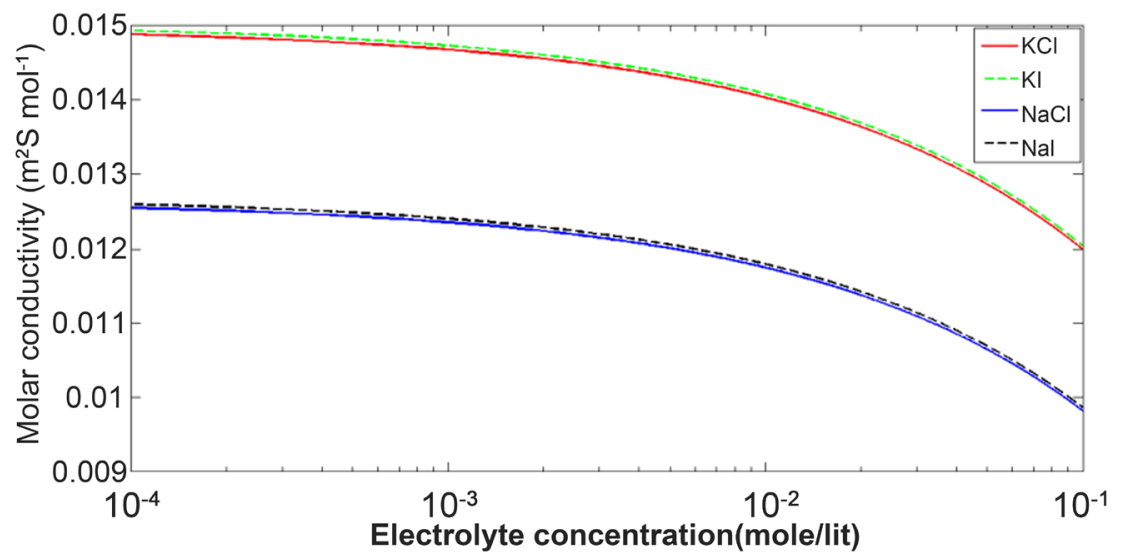

Figure 5. The variation of the molar conductivity with electrolyte concentration for different electrolytes.

the same are larger than those of $\mathrm{NaCl}$ and $\mathrm{NaI}$ that are almost the same. As stated later in this section, the zeta potential in magnitude is larger in electrolytes containing cations of $\mathrm{Na}^{+}$than that in electrolytes containing cations of $\mathrm{K}^{+}$. Therefore, the SPC in magnitude for electrolytes containing cations of $\mathrm{Na}^{+}$is larger than that in electrolytes containing cations of $\mathrm{K}^{+}$as observed in Figure 4.

The SPC magnitude as a function of electrolyte concentration is plotted for both samples and four electrolytes (Figure 6). By fitting the experimental data shown by the solid line in Figure 6, the empirical relation between the SPC magnitude and electrolyte concentration is obtained as

$$
C_{S}=3.98 \times 10^{-9} C_{f}^{-0.75}(\mathrm{~V} / \mathrm{Pa}),
$$

where $C_{f}$ is electrolyte concentration.

Equation (5) has the similar form as the empirical expression $C_{S}=1.36 \times 10^{-9} / C_{f}^{0.9123}$ obtained by Vinogradov, Jaafar, \& Jackson (2010) by fitting experimental data collected for sandstone, sand, silica nanochannels, Stainton, and Fontainebleau with electrolytes of $\mathrm{NaCl}$ and $\mathrm{KCl}$ at $\mathrm{pH}=6-8$. Additionally, by fitting experimental data on sand saturated by $\mathrm{NaCl}$ at $\mathrm{pH}=7-8$ which are available in literature, Jouniaux \& Ishido (2012) obtain another expression $C_{S}=1.2 \times 10^{-8} / \sigma_{f}$ ( $\sigma_{f}$ is the fluid conductivity). The relation between fluid conductivity of a $\mathrm{NaCl}$ solution and concentration in the range $10^{-6}$ $\mathrm{M}<C_{f}<1 \mathrm{M}$ and $15^{\circ} \mathrm{C}<$ temperature $<25^{\circ} \mathrm{C}$ is given as $\sigma_{f}=10 C_{f}$ (Sen \& Goode, 1992). Therefore, the expression $C_{S}=1.2 \times 10^{-9} / C_{f}$ is deduced from Jouniaux \& Ishido (2012) and that also has the similar form as Equation (5).

The prediction of SPC from electrolyte concentration from Jouniaux \& Ishido (2012) and Vinogradov, Jaafar, \& Jackson (2010) is also shown in Figure 6 (the dashed lines). It is seen that their predictions have the same behavior as that obtained in this work but give larger values at the same electrolyte concentration. The reason for the deviation between the empirical expressions may be due to dissimilarities of electrical conductivity of fluids, fluid $\mathrm{pH}$, mineral composition of porous materials, temperature etc. 


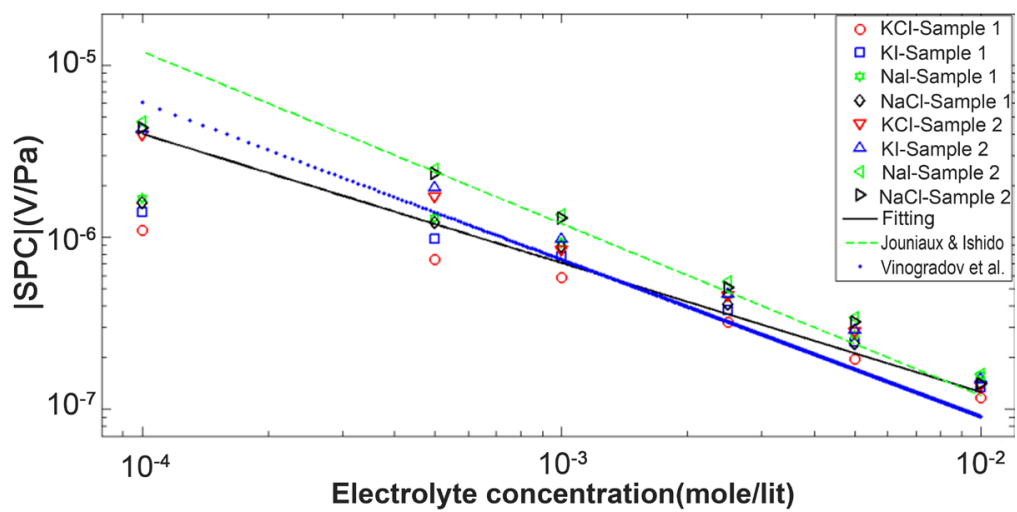

Figure 6. The SPC magnitude versus electrolyte concentration. Symbols are experimental data. Solid line is the fitting line and two other dashed lines are predicted from Jouniaux \& Ishido (2012); Vinogradov, Jaafar, \& Jackson (2010).

\subsection{Zeta Potential}

In order to determine the zeta potential from the measured SPC, the resistance of the saturated samples is measured by an impedance analyzer (Hioki IM3570). The electrical conductivity of the saturated samples $\left(\sigma_{r}\right)$ is then obtained from the measured resistance with the knowledge of the geometry of the sample (the length, the diameter). Based on the electrical conductivity of the saturated samples $\left(\sigma_{r}\right)$ and formation factor $(F)$, the effective conductivity is calculated using $\sigma_{\text {eff }}=F . \sigma_{r}$ and is shown in Table 3. With the measured SPC, the effective conductivity, viscosity and dielectric constant of the fluids, the zeta potential is determined from Equation (2) and is displayed in Table 4. From Table 4, the dependence of the zeta potential on types of electrolyte is shown in Figure 7 for sample 2 for example. The same behavior is also observed for sample 1. Figure 7 shows that the zeta potential in magnitude decreases with increasing electrolyte concentration for all electrolytes as observed in literature (Glover, Walker, \& Jackson, 2012). Additionally, the experimental results also show that among the electrolytes used in this work, $\mathrm{NaI}$ has the most effect on the zeta potential, while the $\mathrm{KCl}$ has the least. This observation is in good agreement with what is stated in Kim et al. (2004) for the zeta potential of silica particles in electrolytes of $\mathrm{NaCl}, \mathrm{NaI}, \mathrm{KCl}, \mathrm{CsCl}$, CsI.

From Table 4, the variation of the zeta potential with electrolyte concentration for different electrolytes in both samples is shown in Figure 8. By fitting the experimental data (solid line), the empirical relation between the zeta potential in magnitude and electrolyte concentration is obtained as

$$
\zeta=-20+5 \log 10\left(C_{f}\right),
$$

where $\zeta$ is in $\mathrm{mV}$ and $C_{f}$ is the electrolyte concentration.

Equation (6) has a similar form as ones available in literature. For example, Pride \& Morgan (1991) obtain the empirical relation between the zeta potential and electrolyte concentration for quartz and $\mathrm{NaCI}$ and $\mathrm{KCI}$ at $\mathrm{pH}=7$ and temperature of $25^{\circ} \mathrm{C}$ as 
Table 3. The effective conductivity of the samples $\left(\sigma_{\text {eff }}\right.$ in $\left.\mathrm{mS} / \mathrm{m}\right)$ at different electrolyte concentrations.

\begin{tabular}{cccccccc}
\hline Sample ID & Electrolyte & $10^{-4} \mathrm{M}$ & $5 \times 10^{-4} \mathrm{M}$ & $10^{-3} \mathrm{M}$ & $2.5 \times 10^{-3} \mathrm{M}$ & $5 \times 10^{-3} \mathrm{M}$ & $10^{-2} \mathrm{M}$ \\
\hline & $\mathrm{NaCl}$ & 15.3 & 19.2 & 25.5 & 47.2 & 77.7 & 130.5 \\
Sample 1 & $\mathrm{NaI}$ & 14.5 & 18.3 & 25.0 & 44.9 & 75.6 & 132.1 \\
& $\mathrm{KCl}$ & 17.1 & 24.0 & 29.5 & 52.4 & 78.9 & 124.3 \\
& $\mathrm{KI}$ & 16.7 & 22.6 & 27.3 & 56.0 & 81.6 & 145.1 \\
& $\mathrm{NaCl}$ & 8.6 & 14.9 & 25.3 & 54.7 & 87.3 & 178.9 \\
\multirow{2}{*}{ Sample 2 } & $\mathrm{NaI}$ & 7.9 & 13.9 & 24.1 & 51.6 & 81.1 & 166.1 \\
& $\mathrm{KCl}$ & 7.2 & 16.5 & 29.1 & 51.2 & 78.3 & 154.8 \\
& $\mathrm{KI}$ & 7.5 & 15.1 & 25.4 & 52.0 & 80.1 & 158.4 \\
\hline
\end{tabular}

Table 4. Zeta potential at different electrolyte concentrations.

\begin{tabular}{cccccccc}
\hline Sample ID & Electrolyte & $10^{-4} \mathrm{M}$ & $5 \times 10^{-4} \mathrm{M}$ & $10^{-3} \mathrm{M}$ & $2.5 \times 10^{-3} \mathrm{M}$ & $5 \times 10^{-3} \mathrm{M}$ & $10^{-2} \mathrm{M}$ \\
\hline \multirow{4}{*}{ Sample 1 } & $\mathrm{NaCl}$ & -34.3 & -33.0 & -32.0 & -27.3 & -26.3 & -25.7 \\
& $\mathrm{NaI}$ & -34.5 & -33.0 & -32.5 & -29.1 & -28.8 & -29.1 \\
& $\mathrm{KCl}$ & -26.5 & -25.2 & -24.3 & -23.7 & -21.9 & -20.5 \\
& $\mathrm{KI}$ & -33.0 & -31.0 & -30.0 & -27.0 & -28.5 & -27.2 \\
& $\mathrm{NaCl}$ & -49.2 & -49.3 & -46.2 & -39.3 & -39.4 & -35.3 \\
\multirow{5}{*}{ Sample 2 } & $\mathrm{NaI}$ & -50.0 & -47.8 & -45.2 & -40.0 & -38.9 & -37.5 \\
& $\mathrm{KCl}$ & -41.2 & -40.0 & -34.5 & -33.0 & -31.3 & -29.8 \\
& $\mathrm{KI}$ & -44.2 & -41.5 & -35.1 & -34.2 & -32.8 & -33.5 \\
\hline
\end{tabular}

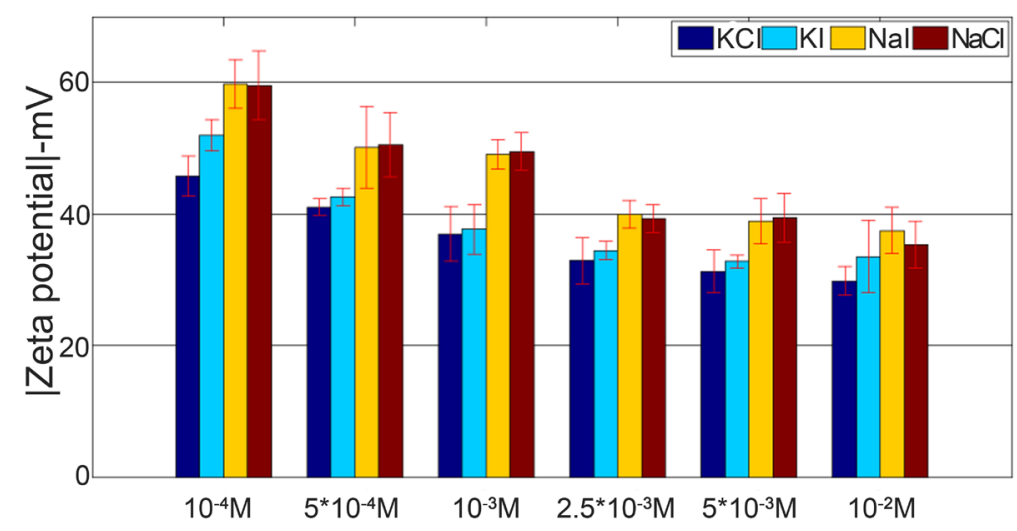

Figure 7. The dependence of the zeta potential in magnitude on types of electrolytes for sample 2 .

$$
\zeta=8+26 \log 10\left(C_{f}\right)
$$

The another relation between the zeta potential and electrolyte concentration is obtained in Vinogradov, Jaafar, \& Jackson (2010) based on published zeta potential data for quartz, silica, glass beads, sandstone, Stainton and Fontainebleau in $\mathrm{NaCl}$ at $\mathrm{pH}=6-8$ as 


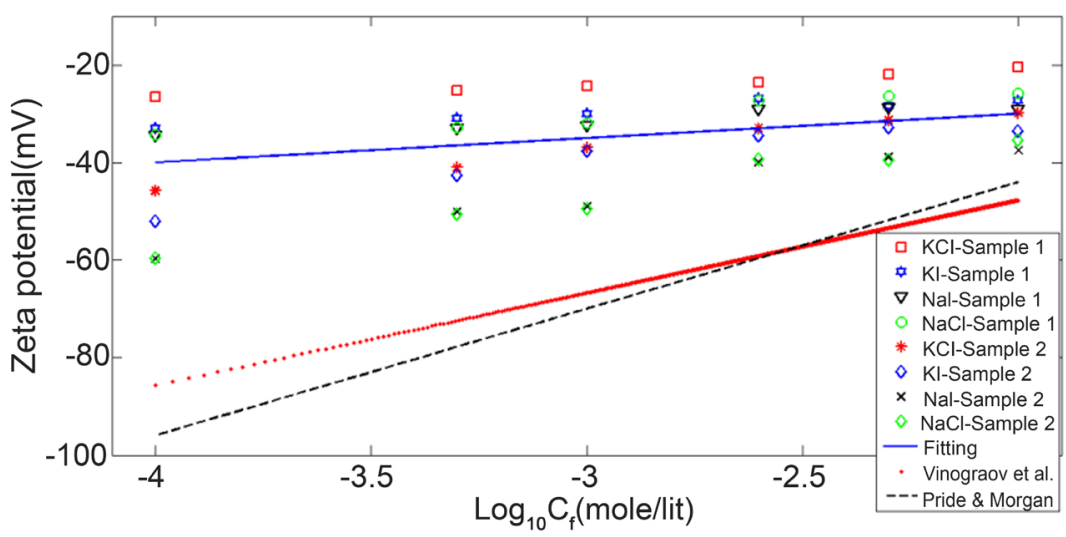

Figure 8. Zeta potential versus electrolyte concentration for both samples and four electrolytes. Symbols are experimental data. The solid line is the fitting one. The dashed lines are predicted from Vinogradov, Jaafar, \& Jackson (2010) and Pride \& Morgan (1991).

$$
\zeta=-9.67+19.02 \log 10\left(C_{f}\right) .
$$

The variation of the zeta potential with the electrolyte concentration predicted from the empirical expressions obtained by Vinogradov, Jaafar, \& Jackson (2010); Pride \& Morgan (1991) is also shown in Figure 8 (dashed lines). It is seen that the predictions overestimate the zeta potential measured in this work. The reason for the overestimation may be due to dissimilarities of mineral composition of materials, fluid conductivity, fluid $\mathrm{pH}$, and temperature etc at which the experiment is carried out. Therefore, the magnitude of zeta potential obtained in this work is different from the values predicted from the available models.

\section{Conclusion}

The measurements of the SPC and the zeta potential of two consolidated rocks saturated with four monovalent electrolytes at different electrolyte concentrations have been performed. The experimental results show that the SPC and the zeta potential in magnitude both decrease with increasing electrolyte concentration for all electrolytes as expected in literature. It is also shown that there is a dependence of the SPC on types of electrolyte for a given sample. This is explained by the dependence of the zeta potential and the electrical conductivity on types of electrolyte. Additionally, the variation of the zeta potential with types of electrolyte is also reported and qualitatively explained. From experimental data on the SPC and the zeta potential, the empirical expressions between the SPC, the zeta potential and electrolyte concentration are obtained. The obtained expressions have the similar forms to those available in literature. However, there is a deviation between them due to dissimilarities of fluid conductivity, fluid $\mathrm{pH}$, mineral composition of porous material and temperature.

\section{Acknowledgements}

This research is funded by Vietnam National Foundation for Science and Technology Development (NAFOSTED) under grant number 103.99-2016.29. Addi- 
tionally, the author would like to thank Dr. Rudolf Sprik for a three month visit at University of Amsterdam and his helpful suggestions for this work.

\section{Conflicts of Interest}

The author declares no conflicts of interest regarding the publication of this paper.

\section{References}

Corwin, R. F., \& Hoover, D. B. (1979). The Self-Potential Method in Geothermal Exploration. Geophysics, 44, 226-245. https://doi.org/10.1190/1.1440964

Glover, P. W. J., Walker, E., \& Jackson, M. D. (2012). Streaming Potential Coefficient of Reservoir Rock: A Theoretical Model. Geophysics, 77, D17-D43. https://doi.org/10.1190/geo2011-0364.1

Jacob, H. M., \& Subirm, B. (2006). Electrokinetic and Colloid Transport Phenomena. Hoboken, NJ: Wiley-Interscience.

Jouniaux, L., \& Ishido, T. (2012). Electrokinetics in Earth Sciences: A Tutorial. International Journal of Geophysics, 2012, 1-16. https://doi.org/10.1155/2012/286107

Kim, S. S., Kim, H. S., Kim, S. G., \& Kim, W. S. (2004). Effect of Electrolyte Additives on Sol-Precipitated Nano Silica Particles. Ceramics International, 30, 171-175. https://doi.org/10.1016/S0272-8842(03)00085-3

Lide, D. R. (2009). Handbook of Chemistry and Physics (90th ed.). Boca Raton, FL: CRC Press.

Luong, D. T. (2014). Electrokinetics in Porous Media. Ph.D. Thesis, Amsterdam: University of Amsterdam.

Mizutani, H., Ishido, T., Yokokura, T., \& Ohnishi, S. (1976). Electrokinetic Phenomena Associated with Earthquakes. Geophysical Research Letters, 3. https://doi.org/10.1029/GL003i007p00365

Morgan, F. D., Williams, E. R., \& Madden, T. R. (1989). Streaming Potential Properties of Westerly Granite with Applications. Geophysical Research, 94, 12.449-12.461. https://doi.org/10.1029/JB094iB09p12449

Nourbehecht, B. (1963). Irreversible Thermodynamic Effects in Inhomogeneous Media and Their Applications in Certain Geoelectric Problems. Ph.D. Thesis, Cambridge, MA: MIT Press.

Ogilvy, A. A., Ayed, M. A., \& Bogoslovsky, V. A. (1969). Geophysical Studies of Water Leakages from Reservoirs. Geophysical Prospecting, 17, 36-62. https://doi.org/10.1111/j.1365-2478.1969.tb02071.x

Pride, S. R., \& Morgan, F. D. (1991), Electrokinetic Dissipation Induced by Seismic Waves. Geophysics, 56, 914-925. https://doi.org/10.1190/1.1443125

Sen, P. N., \& Goode, P. A. (1992). Influence of Temperature on Electrical Conductivity on Shaly Sands. Geophysics, 57, 89-96. https://doi.org/10.1190/1.1443191

Thanh, L. D., \& Sprik, R. (2016). Permeability Dependence of Streaming Potential Coefficient in Porous Media. Geophysical Prospecting, 64, 714-725. https://doi.org/10.1111/1365-2478.12337

Thanh, L. D., \& Sprik, R. (2018). Streaming Potential in Unconsolidated Samples Saturated with Monovalent Electrolytes. VNU Journal of Science: Mathematics-Physics, $34,14-24$. 
Trique, M., Richon, P., Perrier, F., Avouac, J. P. and Sabroux, J. C. (1999). Radon Emanation and Electric Potential Variations Associated with Transient Deformation near Reservoir Lakes. Nature, 399, 137-141. https://doi.org/10.1038/20161

Vinogradov, J., Jaafar, M. Z., \& Jackson, M. D. (2010). Measurement of Streaming Potential Coupling Coefficient in Sandstones Saturated with Natural and Artificial Brines at High Salinity. Journal of Geophysical Research, 115, B12204.

https://doi.org/10.1029/2010JB007593

Wurmstich, B., \& Morgan, F. D. (1994). Modeling of Streaming Potential Responses Caused by Oil Well Pumping. Geophysics, 59, 46-56. https://doi.org/10.1190/1.1443533 